\title{
INQUIRY IN HIGHER EDUCATION FOR SUSTAINABLE DEVELOPMENT: CROSSING DISCIPLINARY KNOWLEDGE BOUNDARIES
}

\author{
Cecília Galvão \\ Instituto de Educação, Universidade de Lisboa; Portugal \\ ISAMB-Instituto de Saúde Ambiental, Universidade de Lisboa; Portugal \\ cgalvao@ie.ulisboa.pt
}

Cláudia Faria

UIDEF-Research and Development Unit in Education and Training, Instituto de Educação, Universidade de Lisboa; Portugal

cbfaria@ie.ulisboa.pt

Wanda Viegas

LEAF-Linking Landscape, Environment, Agriculture and Food, Instituto Superior de Agronomia, Universidade de Lisboa; Portugal

wandaviegas@isa.ulisboa.pt

Amélia Branco

CSG/GHES, ISEG - Lisbon School of Economics and Management, Universidade de Lisboa, Portugal ameliab@iseg.ulisboa.pt

Luís F. Goulão

LEAF-Linking Landscape, Environment, Agriculture and Food, Instituto Superior de Agronomia, Universidade de Lisboa; Portugal

goulao@isa.ulisboa.pt

This is a post-peer-review, pre-copyedit version of an article published in International Journal of Sustainability in Higher Education. The final authenticated version is available online at: https://www.emerald.com/insight/content/doi/10.1108/IJSHE-02-2020-0068/full/html?skipTracking=true. 
Paper submitted: 13-Feb-2020; Paper revised 09-Sep-2020.

\section{Abstract}

This paper aims to present the research results of the impact of a pedagogical approach on students, implemented as a part of the Doctoral Programme in Sustainability Science, which was designed following an innovative model at the University of Lisbon, Portugal. The main drivers include building a new body of interdisciplinary knowledge leading to the application of science to address real problems towards transdisciplinary education.

We aimed to understand if a project work methodology proposed to students, based on an inquiry perspective and dealing with different dimensions of sustainable development, contributed to creating an interdisciplinary solution for a problem on sustainability challenged by food production and consumption, and also to understand if this methodological approach is perceived as important to their learning as professionals and citizens. Data were collected by direct observation, a questionnaire applied to the students, and students' individual reflections.

The results suggest great potential for an inquiry perspective in trying to solve a real problem. Students' proposals were realistic, viable, and complementary enough to collectively contribute in response to the global problem. The use of approaches acquired from different areas of knowledge was clear, and the project methodology was well understood. Students considered the experience very rewarding in terms of learning and contributing positively to their personal and professional development.

This Doctoral programme is anchored in a progressive continuum encompassing holistic debates with a multidisciplinary team of professors in environments that promote interdisciplinary attitudes and new knowledge, and also project work aimed at guiding students to transdisciplinary learning, which constitutes an innovative form of dealing with the complex challenges created by the science of sustainability.

Keywords: Inquiry; Sustainability science; Project work; Transformative higher education; Interdisciplinary learning; Transdisciplinary learning

Paper type: Case study

This is a post-peer-review, pre-copyedit version of an article published in International Journal of Sustainability in Higher Education. The final authenticated version is available online at: https://www.emerald.com/insight/content/doi/10.1108/IJSHE-02-2020-0068/full/html?skipTracking=true. 


\section{INTRODUCTION}

The challenges faced by society are complex and multidimensional, leading to new paradigms associated with sustainability. To be promoters of change, 21 st century professionals must be endowed with solid scientific knowledge and, most importantly, have the capacity to incorporate it to understand the interactions among global, natural, social, and human systems, and how such interactions affect sustainability contexts (Caeiro et al., 2013; UNESCO, 2015).

Societal challenges are complex and usually correspond to open questions with neither a single answer nor unique explanations. Solutions should be based on scientific principles, theories, and data, however they cannot be determined solely from scientific considerations, since other factors (e.g., social, political, economic, ethical, behavioural, and cultural) can influence public perceptions and decision makers (Klein, 2006; Roberts, 2011). In the search for a solution to socio-scientific problems, individuals are led to mobilize dialogical discourses of a deliberative nature, in which they must reason, criticize, and justify, that is, they have to argue by using evidence. Hence, addressing sustainability clearly demands scientific literacy (understood in a comprehensive view of culture) to enable citizens to take and act in the defence of certain positions in an informed and well-founded way (European Commission, 2015; Bencze and Alsop, 2014). Scientific culture in a knowledgeable society is necessarily literacy in action allowing the use of learning to deal with situations in which science and technology are related to daily life and the professional activity of citizens.

Building a new scientific area of Sustainability Science requires information assimilation and integration into one's knowledge base and the mastery of tools that are seldom addressed by individual disciplines and scientific areas. There is a growing awareness that universities should work to engage students in tackling local and global challenges and, most importantly, that these challenges are seldom adequately addressed by a single discipline (Huot et al., 2020; Wilson and Zamberlan, 2012). Today, disciplinary science contributes to understanding the function of the various pieces that make up our world but lacks the understanding of how these parts relate to each other and the world (Pellegrino and Hilton, 2012). Hence the need for new knowledge results from the conscious merger and symbiosis of the perspectives of and information from science, economics, technology and politics (Mitcham and Frodeman, 2003).

According to the Zurich Approach to knowledge creation (resulting from the 2000 Zurich Transdisciplinary Conference), this new knowledge is transdisciplinary and emerges contextually in the application in real life, involving science, technology and society (McGregor, 2014, 2015). Aligned with this approach, there is a need to reverse the prevalent scenario, in which the problems addressed by the academic disciplines in higher education stemmed from science and not from the real world (McGregor, 2014, 2015). The Zurich approach called for context-driven,

This is a post-peer-review, pre-copyedit version of an article published in International Journal of Sustainability in Higher Education. The final authenticated version is available online at: https://www.emerald.com/insight/content/doi/10.1108/IJSHE-02-2020-0068/full/html?skipTracking=true. 
problem-focused work involving a combination of existing disciplinary knowledge in concert with practitioners who would use the results of the transdisciplinary research.

Under this scenario, the required change to reach sustainability needs a responsive pedagogical model that is also attentive to the transition to new forms of skill acquisition and knowledge building. The main drivers of learning include ultimately building a new body of transdisciplinary academic knowledge in support of the application of science to address real problems using transdisciplinary research attentive to the integration of knowledge and innovation with the participation of society and citizens (i.e., Mode 2 learning; see McGregor, 2014).

The Doctoral Programme in Sustainability Science, which was designed following an innovative model at the University of Lisbon and addresses the triangle 'Resources-Food-Society,' focuses on food production and consumption behaviours and attitudes and how they impact global and local sustainability. To address this challenge, this pioneering programme seeks transformative education that challenges both professors and students' attitudes. The idea of sustainability develops around the integration of six complementary dimensions: Human and Environmental Health; Economy, Management and Marketing; Social Practices; Policy, Institutions and Governance; Technologies and Innovation; and Ethics and Values. The programme is underpinned by

The challenge to new knowledge guided by understanding how integrations between ecology and socioeconomics affect sustainability contests, and designed for successful professionals and students seeking to turn knowledge into tangible results, with Theses offered in a university environment, in a business/industry environment, or in the students' specific professional work context - an innovative typology that explores the double translation between research and practice.

(ii) Transformative education to create impact to deliver a responsive pedagogical model attentive to new forms of skills acquisition and knowledge building combining interdisciplinarity with immersive education processes.

To accomplish its goals, this Doctoral Programme is unique, because it combines a truly interdisciplinary orchestration of its faculty members by gathering a wide range of disciplinary knowledge committed with a shared responsibility between natural sciences and social sciences in the coordination, organisation, and teaching of each curricular unit and thesis supervision. Forty-seven faculty members from 17 schools are engaged, and two coordinators with different scientific competencies are mobilized for each of the curricular units, which are supported by an

This is a post-peer-review, pre-copyedit version of an article published in International Journal of Sustainability in Higher Education. The final authenticated version is available online at: https://www.emerald.com/insight/content/doi/10.1108/IJSHE-02-2020-0068/full/html?skipTracking=true. 
integrative syllabus designed by multidisciplinary teaching staff. Moreover, a collaborative experience that relies on sharing all class materials and maintaining a permanent bidirectional work channel was established between students and professors through an Information and Communications Technology (ITC) e-learning platform.

The central component of the pedagogical approach is Project work, following Morin's (1991; 2002) multidimensional thinking and the characteristics of intentionality, autonomy, innovation, cooperation, complexity, and uncertainty (Boutinet, 1996; Fried-Booth, 1986). The concept of project was introduced in language and the educational context during the progressive education movement in the beginning of the 20th century in the United States of America (USA) having as central reference John Dewey's (1859-1952) thoughts and pedagogical contributions. Dewey conceived education in terms of experience and advocated an open pedagogy that is centred on students' learning by doing (Dewey, 1938/2005).

The concept of project, according to William H. Kilpatrick (1871-1965), emerges as a possible designation of a concept that seeks to integrate the intentionality of action, personal commitment to its realization, and its insertion in a social context (Kilpatrick, 1918/2006). Respectively, the acquisition and integration of new knowledge is rooted in project teamwork, autonomous work, and the use of information and communication technologies with professors monitoring and supervising through discussions and debates that promote interdisciplinary thinking and, ultimately, transformative and transdisciplinary learning outcomes.

Today, higher education cannot be detached from a strong commitment to sustainability (Lozano and Lozano, 2014; Cortese, 2003). The road map followed to date is usually restricted to the introduction of topics about sustainability within the educational curriculum and the development of key skills and competencies that enhance sustainability while keeping the current organisation in subject units or courses (i.e., non-integrated fragmentation). Education plays a decisive role in the science of sustainability (Barth and Michelsen, 2013); universities need to go further towards a critical and complex perspective (Segalas et al., 2012).

To that end, this Doctoral Programme in Sustainability Science is a novel and innovative experience. In this paper, we present results about the impact on students' learning of a collaborative experience towards simultaneous interdisciplinary and transdisciplinary knowledge creation. The former relies on debating the interception, nexus approaches, and putative tradeoffs of topics proposed by professors dedicated to at least three different scientific areas in the same subject-driven session. The latter relies on inquiry scenarios, to which students, working in groups, should contribute to solving real and contemporary problems framed by local multidimensional contexts and attentive to the dimensions recognized in the Zurich Approach to

This is a post-peer-review, pre-copyedit version of an article published in International Journal of Sustainability in Higher Education. The final authenticated version is available online at: https://www.emerald.com/insight/content/doi/10.1108/IJSHE-02-2020-0068/full/html?skipTracking=true. 
knowledge production. The challenge was a central pedagogical component in the organisation of four curricular units, which were paired according to common underlying themes to cope with a same project-work starting point. It was anticipated that the results would relate to two project work problems beyond academic disciplines.

\section{METHOD}

To understand the impact of the adopted pedagogical model on students' learning and their perceptions, we focused on the organisation of four curricular units of the Doctoral Programmes' first semester: 'Use of Resources: Soil and Water', 'Biodiversity and Ecosystems Services', 'Social Practices, Food and Health' and 'Sustainable Development of Value Chains and Territories'. These units were paired according to common underlying themes, and two inquiry scenarios were created using local multidimensional contexts, to which students, working in groups, were asked to contribute proposals.

The first inquiry scenario considered the need to take urgent action to reduce greenhouse gas emissions from agriculture production so as to mitigate climate change and its impact and was framed under the scope a pair of curricular units: 'Use of Resources: Soil and Water' and 'Biodiversity and Ecosystems Services'. Students were challenged to work on a multilevel explanation model and present a critical proposal for an adaptation programme in the specific ecosystem of the Tagus 'Lezírias' while taking into consideration that any organisation should be aware of the implications of their activity within the expectation of reducing emissions by twothirds of today's levels (Project work for Problem 1).

In the second inquiry scenario, while working the other pair of curricular units ('Social Practices, Food and Health' and 'Sustainable Development of Value Chains and Territories'), the problem collectively addressed the need to devise a city-wide planning model for the scenario of an intermunicipality agreement in the Lisbon metropolitan region that determines the supply of public markets with at least 60\% local products (Project work for Problem 2).

The learning outcome assessment of groups' intermediate and final work was based on several rubrics created for the assessment of oral presentation and written work (Galvão et al., 2016). These rubrics were discussed with the students and teachers from the beginning of the course. The criteria for the final written work were structure and clarity of the text, relevance of the identified issues, theoretical foundation, consistency and quality of the different components of project-work, and the critical perspective on the overall project. Each criterion was assessed from 1 to 4 , considering several descriptors as the basis.

This is a post-peer-review, pre-copyedit version of an article published in International Journal of Sustainability in Higher Education. The final authenticated version is available online at: https://www.emerald.com/insight/content/doi/10.1108/IJSHE-02-2020-0068/full/html?skipTracking=true. 
The goals of this research were to discern i) the doctoral students' learning outcomes concerning the level of contribution to solve a problem on sustainability when enrolled in a project based on an inquiry perspective dealing with different dimensions and ii) their perceptions of this methodological approach as important to their learning as professionals and citizens.

Additionally, the research strived to understand 1) the potentialities and advantages of following a project-work based on an inquiry perspective in trying to solve a real problem from students' emergent transdisciplinary perspective; 2) the difficulties students experienced with this type of learning strategy; 3) the students' perceptions concerning the potentialities, advantages and drawbacks of project work to their professional and personal development; and 4) the perceived trade-offs of working a limited number of dimensions and having to rely on their colleagues' complementary work to reach a wider perspective that contributes to a plausible solution.

The research involved the 14 doctoral students from the 2018-2019 enrolment of the Doctoral Programme. Their academic background included Agronomy, Computer Engineering, Ecology, Economy, Environment, Forestry, History, Natural Resources, Policy and International Cooperation, and Veterinary Medicine. Most students simultaneously worked as consultants, were experts in environmental institutions, or managed their own businesses. They ranged in age from $<25$ (one student), 25 and 32 (four students), 33 and 39 years (four students) to $>40$ years (five students).

This heterogeneous cohort of doctoral students was organised into five groups. Each was responsible for researching two specific dimensions per work project, which formed a part of the real problem to be solved. The dimensions through which this Sustainability Programme developed (mentioned above), tackled by each group in addressing the first problem, were not repeated in the second project, meaning that each student had contact with four out of the five approaches to contribute to the proposed solution (see Figure 1). This approach also meant that, in the collective set of the five submitted works, all dimensions were addressed thereby allowing integration and an overall discussion between groups.

Data triangulation was achieved by collecting data via direct observation of the working sessions, a questionnaire applied to the students at the end of the units (Likert scale, with four levels from totally disagree to totally agree, and some open queries for general comments), and students' open individual reflections.

This is a post-peer-review, pre-copyedit version of an article published in International Journal of Sustainability in Higher Education. The final authenticated version is available online at: https://www.emerald.com/insight/content/doi/10.1108/IJSHE-02-2020-0068/full/html?skipTracking=true. 
Figure 1. Dimensions explored by each group of students to solve the problems.

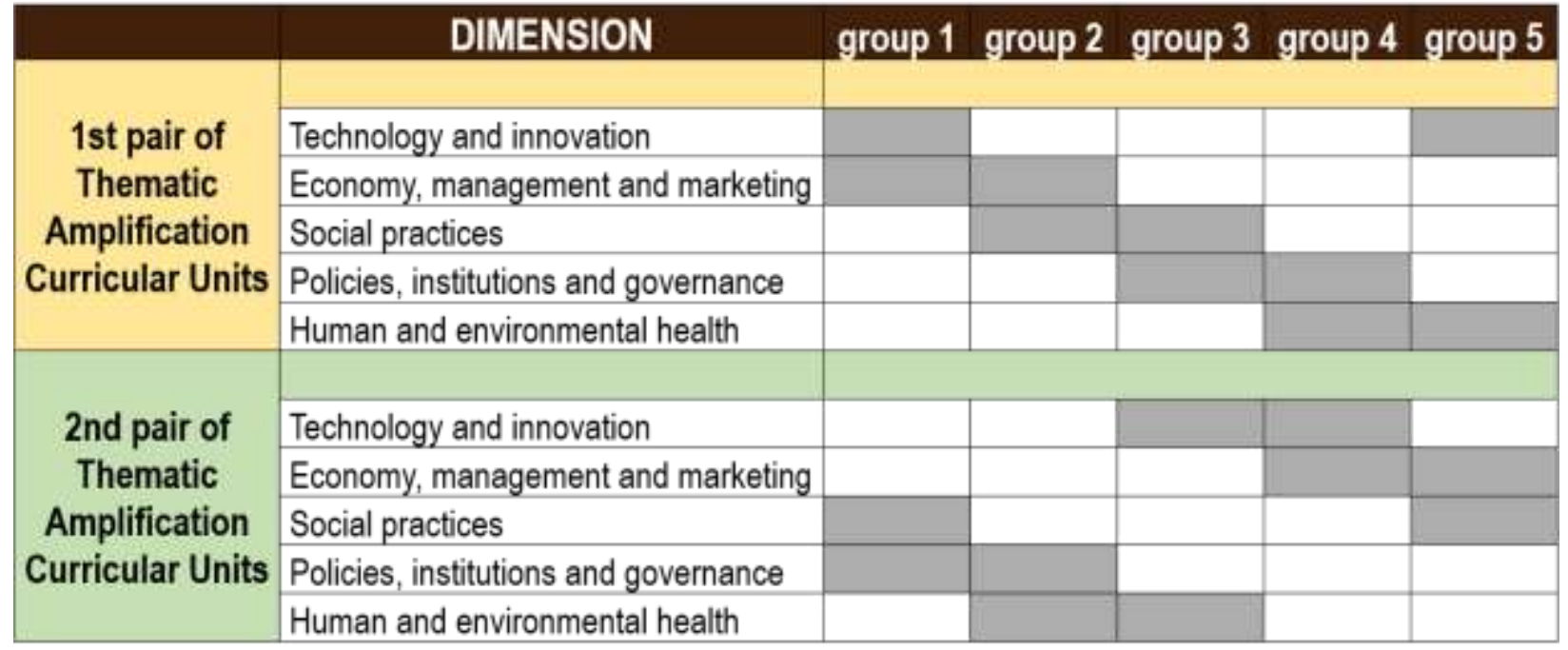

Questionnaire Dimensions

- Overall appreciation of the course

- Block 1- Immersive sessions in interdisciplinary environments

- Methodology

- Materials provided

- Organisation

- Autonomous work

- $\quad$ Block 2. Multi-perspective project-work

- Project-work methodology

- Organisation of the project work

○ Team Work

- Learning Assessment

- Feedback and Assessment Criteria

- Global Evaluation

- General comments

This is a post-peer-review, pre-copyedit version of an article published in International Journal of Sustainability in Higher Education. The final authenticated version is available online at: https://www.emerald.com/insight/content/doi/10.1108/IJSHE-02-2020-0068/full/html?skipTracking=true. 
The written reflective orientations

- What I have enjoyed doing the most throughout this work? Why?

- What I have enjoyed doing the least throughout this work? Why?

- I had more difficulties in...

- This research work was very interesting, interesting, and uninteresting because...

- What I have learned most with this work.

\section{RESULTS}

The results obtained must be framed by the strategy employed in preparing the course. During the preparation stage, all professors were very enthusiastic in developing the curricular units using the collective and participatory rounds of their debate with colleagues who had distinct academic backgrounds, ranging from natural/exact sciences to humanities/social sciences. This collegial effort resulted in a final syllabus that could hardly be connected to a specific disciplinary knowledge domain. Equally, during the first edition, all professors were fully engaged with the pedagogical model agreed and were active in preparing extended summaries, and selected core materials to frame their topics, and producing dedicated e-learning materials, including professional video records of short lessons. All materials were made available in the dedicated ICT e-learning platform to which students were granted access one week before the corresponding session. Most importantly, 'in class' sessions always took place with the simultaneous participation of 3-5 professors (according to each specific session) with distinct knowledge backgrounds and academic competencies, resulting in integrative academic debates that successfully challenged concept and methodological confrontations. Field visits related to the problem with the project-work were organised and were successful in joining a wide group of professors with competences in a significant number of disciplines to offer interdisciplinary critical rationale. The project work was evaluated through a methodology rooted in individual evaluation by professors from distinct disciplinary areas, using a previously agreed grid, followed by discussions to reach consensual grades, which additionally revealed a great potential to pave the way for their interdisciplinary thinking.

A synthesis is now presented of students' critical proposals for adapting a programme in Tagus 'Lezírias' so it reduces greenhouse gas emissions from agricultural production. This collection serves to illustrate the success of this learning strategy:

- Create an agricultural and forestry technology hub Companhia das Lezírias with a new model of partnerships with research entities, integration of new emerging companies and spin-off companies, and sharing resources.

This is a post-peer-review, pre-copyedit version of an article published in International Journal of Sustainability in Higher Education. The final authenticated version is available online at:

https://www.emerald.com/insight/content/doi/10.1108/IJSHE-02-2020-0068/full/html?skipTracking=true. 
- Alter the rice irrigation method for intermittent flooding, the culture of Salicornia, and the construction of a Built Humid Zone.

- Change conventional practices (agricultural and other). Reflections on possible ways to address these issues ended up defining the guidelines of the work: the systemic approach; the emphasis on effectiveness and efficiency; the perspective of 'change promoters'.

- Draw on contributions from the energy field by (a) replacing traditional sources of fossil fuels (such as agricultural diesel with clean sources), (b) introducing energy-saving mechanisms (such as the use of drone groups for monitoring), (c) dispersing chemical agents (such as pesticides) and (d) introducing techniques for the absorption of carbon and methane.

- Focus on the adequacy of cattle stock and the management of these animals in the finishing phase by using ideas such as (a) mitigation measures and (b) the promotion of natural regeneration of the plain by the temporary exclusion of grazing as an adaptation measure.

In the evaluation process, professors recognized the matrix structure in several works, incorporating the learning materials of the curricular units and the five above mentioned dimensions selected due to their significance to sustainable development. The feasibility of the proposals considering the local socioeconomic framework was also recognized.

Analysis of the questionnaire data (see Table 1: parts 1,2, and 3) revealed that students 'partly or totally agreed' with most of the sentences related to an appreciation of the Doctoral course in general, and the project work in particular, specifically in the case of the sentences 'Learn new subjects', 'It led to more interdisciplinary fields', 'The starting problems were adequate for learning about sustainability' and 'The documentation and materials were relevant for projectwork' (highlighted in bold).

This is a post-peer-review, pre-copyedit version of an article published in International Journal of Sustainability in Higher Education. The final authenticated version is available online at: https://www.emerald.com/insight/content/doi/10.1108/IJSHE-02-2020-0068/full/html?skipTracking=true. 
Table 1 - General Results

1. Overall Appreciation of the Course by the Students

\begin{tabular}{|c|c|c|c|c|}
\hline & Minimum & Maximum & Mean & $\begin{array}{l}\text { Std. } \\
\text { Deviation }\end{array}$ \\
\hline Learn new subjects & 2 & 4 & 3,50 & 850 \\
\hline Recall or consolidate previous knowledge & 2 & 4 & 3,30 & 675 \\
\hline Develop or Improve working methods and techniques & 1 & 4 & 3,30 & 1,160 \\
\hline Clarify solutions to practical problems & 2 & 4 & 3,30 & ,823 \\
\hline Answered to my training needs & 1 & 4 & 3,10 & 1,287 \\
\hline $\begin{array}{l}\text { I would prefer to have additional and new } \\
\text { knowledge about my scientific area }\end{array}$ & 1 & 4 & 2,80 & 1,135 \\
\hline Substantiate and fit a better professional practice & 1 & 4 & 3,20 & ,919 \\
\hline Reflect on professional Practice in sustainability & 2 & 4 & 3,70 & 675 \\
\hline The formation met my expectations & 1 & 4 & 3,20 & 919 \\
\hline
\end{tabular}

\section{Immersive Session Methodology}

\begin{tabular}{|c|c|c|c|c|}
\hline & Minimum & Maximum & Mean & $\begin{array}{l}\text { Std. } \\
\text { Deviation }\end{array}$ \\
\hline $\begin{array}{l}\text { The methodology of immersive sessions was } \\
\text { appropriate }\end{array}$ & 1 & 4 & 2,60 & 1,350 \\
\hline $\begin{array}{l}\text { The methodology of immersive sessions facilitated } \\
\text { content learning }\end{array}$ & 1 & 4 & 2,70 & 1,337 \\
\hline $\begin{array}{l}\text { The students were involved in the development of the } \\
\text { sessions }\end{array}$ & 1 & 4 & 3,00 & 1,155 \\
\hline It provided an exchange of experiences between students & 1 & 4 & 2,80 & 1,033 \\
\hline Theory and professional practice were related & 2 & 4 & 3,30 & ,823 \\
\hline It led to more interdisciplinary fields & 1 & 4 & 3,40 & 966 \\
\hline Contents of Social and Natural Sciences were balanced & 1 & 4 & 3,10 & 1,287 \\
\hline Difficulty in understanding my role & 1 & 4 & 2,40 & 1,265 \\
\hline Difficulty in understanding students role & 1 & 4 & 2,70 & 1,160 \\
\hline $\begin{array}{l}\text { The methodology is appropriate for Doctoral program } \\
\text { objectives }\end{array}$ & 1 & 4 & 2,70 & 1,252 \\
\hline
\end{tabular}

\section{Project-Work Methodology}

\begin{tabular}{|c|c|c|c|c|}
\hline & Minimum & Maximum & Mean & $\begin{array}{l}\text { Std. } \\
\text { Deviation }\end{array}$ \\
\hline $\begin{array}{l}\text { The project work methodology was appropriate to the } \\
\text { formation objectives }\end{array}$ & 1 & 4 & 2,90 & 1,197 \\
\hline The project work methodology facilitated content learning & 1 & 4 & 2,90 & 1,370 \\
\hline $\begin{array}{l}\text { The starting problems were adequate for learning about } \\
\text { sustainability }\end{array}$ & 1 & 4 & 3,60 & ,966 \\
\hline $\begin{array}{l}\text { The documentation and materials were relevant for the } \\
\text { project work }\end{array}$ & 1 & 4 & 3,60 & ,966 \\
\hline The discussions were relevant for project work & 2 & 4 & 3,40 & ,699 \\
\hline The students were involved in the project's development & 1 & 4 & 3,20 & 1,033 \\
\hline It provided an exchange of experiences between students & 1 & 4 & 2,90 & ,876 \\
\hline Theory and practice were related & 2 & 4 & 3,50 & ,707 \\
\hline The project was concluded & 2 & 4 & 3,40 & ,699 \\
\hline The duration of the formation allowed the accomplishment & 1 & 4 & 3,10 & 1,101 \\
\hline
\end{tabular}

of the project work

This is a post-peer-review, pre-copyedit version of an article published in International Journal of Sustainability in Higher Education. The final authenticated version is available online at:

https://www.emerald.com/insight/content/doi/10.1108/IJSHE-02-2020-0068/full/html?skipTracking=true. 


\begin{tabular}{|c|c|c|c|c|}
\hline $\begin{array}{l}\text { The field trip was important to the execution of the project } \\
\text { work }\end{array}$ & 1 & 4 & 3,00 & 1,054 \\
\hline $\begin{array}{l}\text { I had difficulties in understanding the process of the } \\
\text { project work }\end{array}$ & 1 & 4 & 1,90 & 1,101 \\
\hline $\begin{array}{l}\text { I had difficulties in understanding my role in these } \\
\text { sessions }\end{array}$ & 1 & 4 & 1,50 & 972 \\
\hline $\begin{array}{l}\text { I had difficulties in understanding the student's role in } \\
\text { these sessions }\end{array}$ & 1 & 4 & 1,78 & 1,302 \\
\hline $\begin{array}{l}\text { The methodology is adequate for achieving the objectives of } \\
\text { this program }\end{array}$ & 1 & 4 & 3,00 & 1,155 \\
\hline $\begin{array}{l}\text { Project work in only suitable for students with high } \\
\text { learning capacities }\end{array}$ & 1 & 4 & 2,40 & 1,265 \\
\hline
\end{tabular}

\begin{tabular}{lllll}
\hline \hline \multicolumn{1}{c}{ 4. Team-work } & & & & \\
\hline \hline & Minimum & Maximum & Mean & Deviation \\
\hline I enjoyed working in a group & $\mathbf{2}$ & $\mathbf{4}$ & $\mathbf{3 , 5 0}$ & $\mathbf{3 0 7}$ \\
I had some difficulty in depending on the work of others & $\mathbf{1}$ & $\mathbf{4}$ & $\mathbf{2 , 9 0}$ & $\mathbf{1 , 1 9 7}$ \\
I would prefer to work all the dimensions by myself & 1 & 4 & 1,90 & 1,101 \\
I had some difficulty in accepting the perspectives of others & 1 & 4 & 1,70 & 1,252 \\
I felt the teamwork was a very rich experience & 1 & 4 & 3,10 & 1,101 \\
I think I would reach a better solution if I worked by myself & 1 & 4 & 1,30 &, 949 \\
& & & & \\
\hline
\end{tabular}

(Likert scale: 1=totally disagree; 2=partially disagree; 3=partially agree; 4=totally agree)

In the following presentation and analysis of the results, four research questions (RQ) were considered:

$R Q 1) T o$ understand the potentialities and advantages of following a project work, based on an inquiry perspective, in trying to solve a real problem from the students' acquired transdisciplinary perspective.

Overall, considering the project-work methodology (Part 3 of the questionnaire), a majority of the students 'partially agree' with the sentences used, highlighting the appropriateness of the starting problems, documentation used, relevance of discussions, and relations between theory and practice (see the sentences highlighted in bold). They perceived that the project was concluded, and this is a good indicator of a positive individual contribution to a collective problem solution.

In their own words (underlined by us):

Very important to the approach theory to practice. The possibility of understanding the real and multiple problems that enterprises and institutions face in implementing better practices and more sustainable options. Integrative problem solving I think it is very

This is a post-peer-review, pre-copyedit version of an article published in International Journal of Sustainability in Higher Education. The final authenticated version is available online at: https://www.emerald.com/insight/content/doi/10.1108/IJSHE-02-2020-0068/full/html?skipTracking=true. 
important to bring theory into practice and adapt academic research into practical and concrete solutions, not only on large-scale and high-level decision makers. (Student 2, general comment)

The project was clearly related to real problems. The societal challenges were explicit and covering subjects connected to several disciplines, being able to establish a multidisciplinary vision. The sustainability triangle (economy, society, and environment) was the basis of our work that explored and responded in various ways. Through this method, the knowledge produced in this course can contribute to solving current problems. (Student 3, general comment)

'This learning experience provides the opportunity to put in practice the acquired knowledge and creates a "real-life" like experience, which is the best way to integrate knowledge'. (Student 9, general comment)

This research work was very interesting, because it was possible to increase the knowledge to my academic background and research areas. With research work, I was able to understand, in a more feasible way, certain problems presented in class. (Student 3 , written reflection)

The comments of the students focus on the perceived advantages of this kind of approach and they figure out, above all, the relation between theory and practice, and the importance of working on a real situation in accordance with context-based perspectives and problem-based learning in several projects across Europe nowadays (Galvão et al., 2017) and even earlier (Nentwig and Waddington (Eds.), 2005), and in accordance with the Zurich Approach. The perception of learning different subjects, useful for solving real-life problems, is also present, which is a very important acquisition when dealing with a broad area as sustainability (UNESCO, 2015).

\section{$R Q 2)$ To understand the difficulties experienced by students with this type of methodology.}

Looking at the answers to the closed questions in the questionnaire, parts 2 and 3, we can observe that some of them point to the existence of some difficulties (related to the students' overall role, in general, and also specifying the individual respondent role) associated with the immersive sessions (sentences in bold). In the case of the difficulties associated with the project methodology, it seemed that a majority of students did not experience many difficulties in understanding the process associated with this type of work as well as their role in it ("partially disagree' with the sentences). However, there seems to be no consensus concerning the potential of the methodology used during the immersive sessions, since the average response is midway

This is a post-peer-review, pre-copyedit version of an article published in International Journal of Sustainability in Higher Education. The final authenticated version is available online at: https://www.emerald.com/insight/content/doi/10.1108/IJSHE-02-2020-0068/full/html?skipTracking=true. 
between partially disagree and partially agree with the sentences about its adequacy to the objectives of the programme. Moreover, some students think that it is a methodology more suitable for high-level students.

The general comments and written reflections provide explanations for these difficulties.

\section{Inherent to the students' background and profession}

Time constraints and distance to access information, and fully understand the subject to be solved. (Student 2, general comment)

Because of my background, sometimes, there has been a feeling of lack of preparation to meet the required objectives and required some deep work on my part. (Student 9, written reflection)

For people like me, who also have demanding professional endeavours, it has also been difficult to balance and dedicate the desired time to studies. (Student 2, written reflection)

I have experienced more difficulties in some technical aspects. This situation is also perhaps due to the volume of concepts we had to work on, which led to fewer difficulties. Nevertheless, by reading the case studies and specific examples, the difficulties were overcome. In addition, the teachers were available to clarify doubts, something also very useful. (Student 3, written reflection)

\section{Inherent to external situations.}

The only aspect in dealing with real problems is the fact that the contact with some institutions does not have actual and concrete data on some of the issues. Although this fact is not related to the doctoral course, I think it is important to mention it. (Student 3, written reflection)

The field visits were programmed too early to be properly used by the students. Teams for the different projects should allow change, to take the most advantage of the collaboration of students with different backgrounds. (Student 9, written reflection)

The following comment is very interesting, once the student relates to the difficulties faced in the course with those probably found in reality:

From my point of view, doing project-work focused on a real problem is such a good idea that any constraints I felt were the normal constraints that I would feel in a simulation

This is a post-peer-review, pre-copyedit version of an article published in International Journal of Sustainability in Higher Education. The final authenticated version is available online at: https://www.emerald.com/insight/content/doi/10.1108/IJSHE-02-2020-0068/full/html?skipTracking=true. 
situation. With the difference that, since it is a real problem I had the possibility to feel real constraints. (Student 5, general comment)

$R Q 3)$ To understand the students' opinions concerning the potentialities and advantages or the drawbacks of project work methodology for their professional and personal development.

In general, students 'partially agree' with most of the sentences (Part 1 of the questionnaire). In the case of the promotion of learning about new subjects and reflection on professional practice in sustainability, a majority felt that it was actually achieved. All of the sentences used are positive in relation to the course, except the one, 'I would prefer to have more and new knowledge about my scientific area of formation', that points to a need not totally satisfied (Bold in table 1), since a majority of the students 'partially agree' with this sentence.

In their own words:

Looking at real problems, the main advantages of this form of research was the specific delimitation of an important question inviting us to create a workable way of responding. This has led us to create circumscribed solutions. (Student 3, general comment)

It makes the connection between the academia and the professional world, and this allows the students to feel the real deal. (Student 5, general comment)

Bridge the information transmitted in class with a possible professional path of students and the possibility of creating solutions that can be actually considered within the companies' context.(Student 9, general comment)

To provide the tools and methods to replicate a strategy in a professional environment. (Student 10, general comment)

In addition, the written reflections bring us some very rich narratives about learning, and personal and professional growth. We present two examples:

My experience with this formation is both challenging and rewarding. It has been a wonderful learning experience and has helped me broaden my knowledge, or lack of knowledge, about the subjects of sustainability, resilience, and adaptability. I have also enjoyed getting to know all the people with different backgrounds whose perspectives and knowledge have helped me evolve my motivations and solution seeking path. (Student 2, written reflection)

This is a post-peer-review, pre-copyedit version of an article published in International Journal of Sustainability in Higher Education. The final authenticated version is available online at: https://www.emerald.com/insight/content/doi/10.1108/IJSHE-02-2020-0068/full/html?skipTracking=true. 
This $\mathrm{PhD}$ has been, for me, a personal and professional growth experience. The part I have enjoyed more has been the interdisciplinary panel discussions. It has given me the opportunity to contact experienced and skilled professionals and researchers from the most varied areas of knowledge, opening horizons, and inciting the will to become an active part in sustainability-related problem solving. (Student 9, written reflection)

$R Q 4)$ To understand the perceived trade-offs of working a limited number of dimensions and therefore rely on colleagues' complementary work to reach a wider perspective that contributes to a result.

In the context of teamwork (Part 4 of the questionnaire), there are only two positive sentences (highlighted in bold), whereas the other sentences relate to problems with this type of work. Although they seemed to have enjoyed working in a group, they faced a few challenges depending on the work of others.

As an example of a few less satisfactory aspects related to several and different personalities, we have a general comment and an excerpt of a written reflection:

Typical constraints with sessions that include multiple persons and personalities, where more extrovert people can monopolize the subject and add a bias on the discussion, giving less space to other subjects that introvert people could bring. (Student 2, general comment)

Not every student is from the same area of expertise, which should reinforce the need to elucidate most of the key ideas of the sessions. Also, at some point, it was uninteresting to sit and watch random debates that did not add knowledge; a simple expository class from the teachers might have been more profitable. (Student 1, written reflection)

Although there are fewer positive perspectives, there are other students who appreciate group work:

First of all, I want to congratulate all the professors and other people from the university that made this PhD happen. I am really enjoying each piece of it, and it is only the beginning. Considering the 'usual' problems that can occur when different personalities get together, I feel that the synergies built between teachers and students were very interesting and productive. Each student has a different background and professional expertise, which is a win-win situation. (Student 5 , written reflection)

Probably the most important piece of knowledge I will take from this course is that for solving sustainability-related problems, the best approach is a team approach, with

This is a post-peer-review, pre-copyedit version of an article published in International Journal of Sustainability in Higher Education. The final authenticated version is available online at:

https://www.emerald.com/insight/content/doi/10.1108/IJSHE-02-2020-0068/full/html?skipTracking=true. 
different visions, background, and ideas. I am very thankful to be a part of this first edition. (Student 9, written reflection)

It is natural that students experienced some problems in coordinating different perspectives and ways of understanding subjects to solve the proposed complex problem. They had to deal not only with a large amount of information inside the group, but also with data and knowledge produced by other groups for everything to make sense in response to the global problem. They felt there was insufficient time to accomplish everything they would like to; however, the results were good enough, so in the end they felt successful. As one of the students remarked:

I think this multidisciplinary programme is an adequate and necessary approach to research and reach different solutions for such complex problems like sustainability. (Student 2, written reflection)

The amounts of information students have to deal with, make them view teachers' contributions with their different expertise as an interdisciplinary approach. The objective for the near future for all is the achievement of a transdisciplinary course that, according to Davies and Devlin (2007), involves the collapse of academic boundaries and the emergence of a new discipline.

\section{DISCUSSION}

The Sustainability Science Doctoral Course was designed to progress in two main phases. In the first phase, curricular unit syllabus and teaching were prepared by a large group of professors commonly engaged with disciplinary teaching and research, to promote an environment that prompts interdisciplinary thinking among students. This is in accordance with the idea that students can successfully navigate across professions in workplaces and to effectively contribute to large projects involving a diverse range of roles and responsibilities (Wilson and Zamberlan, 2012). Subsequently, through project-work oriented to real-life questions, professors were expected to create a framework for a new body of transdisciplinary knowledge that is foreseen to be echoed in their teaching methodology and thesis supervision.

Sustainability science involves dealing with very complex challenges, which could be viewed as 'wicked problems' that is, problems that change over time, have scientifically uncertain causes and effects, and involve conflict among different stakeholders (Dentoni and Bitzer, 2015). The current view is that traditional university structures, organised by disciplines, fail to address this type of problem, with an increasing appeal to the need to develop interdisciplinary work (Huot $e t$ $a l ., 2020)$. We can understand what different levels of interdisciplinarity means (Davies and

This is a post-peer-review, pre-copyedit version of an article published in International Journal of Sustainability in Higher Education. The final authenticated version is available online at: https://www.emerald.com/insight/content/doi/10.1108/IJSHE-02-2020-0068/full/html?skipTracking=true. 
Devlin, 2007). According to Davidson (2004), there are a number of variants from 'benign to radical' (p. 3), that can be understood as located on a continuum, starting simply as elective subjects taken from a variety of disciplines related to a general topic (the benign end), moving to a crescent integration of disciplines, until reaching the radical end, that involves the 'collapse of academic borders and the emergence of a new discipline'. This could also be called as 'transdisciplinarity' (Max-Neef, 2005).

These variants are useful when considering how students might progressively develop their transdisciplinary understanding over this Doctoral Programme. Indeed, although there seems to exist an almost consensual idea among students that this course promotes interdisciplinarity work, we can also find a continuum in the work developed. Looking at the teachers' role, we can state that they are claiming the stars of interdisciplinary level, considering that it involves a number of disciplines combining their expertise to address an area of common concern (MaxNeef, 2005). Indeed, they coordinate their contributions to promote an integrated view of the issues under study, leaving the main task of creating new perspectives, needed to provide a breakthrough solution to the wicked problems explored, to the students themselves in the project work component.

Considering the students' work, the pedagogical approach developed in this Doctoral Programme, project teamwork, involving students in dealing with real, complex, and multidimensional problems, boost the conditions to promote the development of new knowledge, as advocated by the Zurich approach. Indeed, the students' proposed solutions suggested that they have already achieved a transdisciplinary level, being capable of proposing new and rich contributions, that combines the perspectives of science, economics, technology, politics and ethics.

This progressive continuum encompassing holistic debates in environments that promote interdisciplinarity, interdisciplinary attitudes and new knowledge, and also transdisciplinary project work is a distinct feature of the University of Lisbon's Sustainability Science Doctoral Programme. Our approach develops by recognizing, but going beyond, both the main competencies that support sustainability pedagogy, such as systems-thinking competence, anticipatory competence, normative competence, strategic competence, and interpersonal competence (Wiek et al., 2011) and the value of case studies in teaching sustainability (Hardin et al., 2016; Sprain and Timpson, 2012). Much of higher education stresses on individual learning and competition. This Doctoral Programme was designed to encourage professors to extend their work into other disciplines and collaborate in an interdisciplinary way. Students are also challenged to participate in the process, emphasizing collaboration and cooperation. The tools to deal with real problems were developed through an innovative programme in contents and work proposals that tried to allow students to be aware of the complexity, uncertainty, and various and,

This is a post-peer-review, pre-copyedit version of an article published in International Journal of Sustainability in Higher Education. The final authenticated version is available online at:

https://www.emerald.com/insight/content/doi/10.1108/IJSHE-02-2020-0068/full/html?skipTracking=true. 
sometimes, conflicting, perspectives, and contemplating different special scales and organisations.

\section{CONCLUSION}

The results reveal a dynamic and fruitful collaboration under a common objective, and suggest great potentialities of the inquiry perspective and project work in trying to solve real problems. The students' proposals were realistic and viable and were complementary enough to contribute to collectively respond to the global problem. The use of combined approaches from different areas of knowledge was accomplished, and the students understood the project methodology. A few challenges concerning teamwork and information management were observed, particularly during the first of the two project works; however significant improvements were attained when the groups addressed the second problem. Students considered the experience to be very rewarding in terms of learning, concerning both the thematic areas and the methodological process with most agreeing that it contributed very positively to their personal and professional valorisation/development. The integration of the disciplinary content during the discussion sessions, applied in the context of a real world-driven, problem-focused work, seems promising as both a strategy to promote transdisciplinary learning and being to deal with sustainability challenges.

The results, especially students' comments and written reflections, reveal the great benefits of project work in a Sustainability Science Doctoral Programme. This will be even more so once this teaching and learning strategy becomes the way to put juxtapose different teachers with diverse knowledge thereby enabling students to assume an active role in mobilizing this knowledge in a more meaningful way.

This project approach will be good preparation for their own thesis project, which must be centred on real problems and employ transversal and transdisciplinary knowledge. Addressing the transversal difficulty highlighted by most students in dealing with the diverse amount of information to extract the most from the immersive classes and debates. To overcome this difficulty, in the second edition of the course held in 2019-2020, the compulsory materials previously made available were revised, and students were asked to present an individual transversal question that integrates the different viewpoints from the various knowledge areas to be discussed with the multidisciplinary trio of professors under the session's common subject. Such questions were made available in the e-learning platform before each session, and guided the interdisciplinary debate and the transdisciplinary critical analyses.

This is a post-peer-review, pre-copyedit version of an article published in International Journal of Sustainability in Higher Education. The final authenticated version is available online at: https://www.emerald.com/insight/content/doi/10.1108/IJSHE-02-2020-0068/full/html?skipTracking=true. 
The students and teachers recognized the intermediate and final presentations of the Project work as very fruitful and constructive. The improvement from one project to another was notable, involving teachers in interdisciplinary and integrative discussions for the achievement of solutions based on consensus and/or conflicts and disciplinary trade-off negotiations.

This programme is sustained by College F3 - Food, Farming, and Forestry - which is a transversal organisation of collaboration on teaching and research of all the 18 associated faculties and institutes of the University of Lisbon. The goals of College F3 are related to economic globalisation in a scenario of climate and demographic changes and resource scarcity, being aware that attitudes in food production and consumption have a huge contribution to global sustainability threats. College F3, where this program is housed, contributes to (a) creating and sharing integrated knowledge towards technological advances and new strategies in the fields of innovation and socio-environmental responsibility and (b) providing substantive sustainability related information to policy makers. F3 interdisciplinary science is also transdisciplinary, because scientists, economic and social actors are called to co-produce and communicate socially relevant knowledge. The Doctoral Programme on Sustainability Science puts into practice the interdisciplinary philosophy of College F3 and paves the way for transdisciplinary learning and teaching.

\section{ACKNOWLEDGEMENTS}

This work was supported by Fundação para a Ciência e a Tecnologia through funding to research units UID/AGR/04129/2020 (LEAF), UIDB/04107/2020 (UIDEF), UIDB/04295/2020 (ISAMB) and UIDB/04521/2020 (CSG/GHES). We would like to thank Editage (www.editage.com) for English language editing.

\section{REFERENCES}

Barth, M. and Michelsen, G. (2013). 'Learning for change: an educational contribution to sustainability science'. Sustainability science, vol 8 n 1, pp. 103-119.

Bencze, L. and Alsop, S. (Eds.). (2014). Activist science and technology education. Springer, New York, NY

Boutinet, J-P. (1996). Antropologia do Projecto. Instituto Piajet, Lisboa.

Caeiro, S., Filho, W., Jabbour, C. and Azeiteiro, U. (eds) (2013). Sustainability assessment tools in higher education institutions. Springer International Publishing Switzerland. DOI: 10.1007/978-3-319-02375-5_12.

Cortese, A.D. (2003). 'The critical role of higher education in creating a sustainable future'. Planning for higher education, vol $31 \mathrm{n}^{\circ} 3$, pp. 15-22.

This is a post-peer-review, pre-copyedit version of an article published in International Journal of Sustainability in Higher Education. The final authenticated version is available online at:

https://www.emerald.com/insight/content/doi/10.1108/IJSHE-02-2020-0068/full/html?skipTracking=true. 
Davies, M. and Devlin, M. (2007). Interdisciplinary higher education: Implications for teaching and learning. Centre for the Study of Higher Education, University of Melbourne.

Davidson, M. (2004). 'Bones of Contention: Using Self and Story in the Quest to Professionalize Higher Education, An Interdisciplinary Approach'. Teaching in Higher Education, vol 9

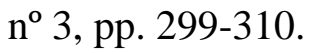

Dentoni, D. and Bitzer, V. (2015). 'The role(s) of universities in dealing with global wicked problems through multi-stakeholder initiatives'. Journal of Cleaner Production, vol 106, pp. 68-78.

Dewey, J. (1938/2005). A concepção democrática da educação [Democratic Conception of education]. Pretexto Editora, Viseu.

European Commission (2015). Science education for responsible citizenship. Report of the Expert Group on Science Education. Luxembourg: European Union. http://ec.europa.eu/research/swafs/pdf/pub_science_education/KI-NA-26-893-EN-N.pdf

Fried-Booth, D. (1986). Project work. Oxford University Press, Oxford

Galvão, C., Baptista, M. and Conceição, T. (2017). 'International science education projects for context based learning'. L. Leite, Dourado, L., Afonso, A. and Morgado, S. (Ed.), Contextualizing teaching to improve learning. The case of science and geography, Nova science Publishers, New York, pp. 201-222.

Galvão, C., Faria, C., Gonçalves, C.and Baptista, M. (2016). Atividades investigativas $e$ avaliação das aprendizagens. $O$ contributo do projeto internacional SAILS. [Inquiry activities and learning assessment. The contribution of international project SAILS]. Instituto de Educação da Universidade de Lisboa, Lisboa.

Hardin, R., Bhargava, A., Bothner, C., Browne, K., Kusano, S., Golrokhian, A., Wright, M., Zhu Zeng, P. and Agrawal, A. (2016). 'Towards a revolution in sustainability education: Vision, architecture, and assessment in a case-based approach'. World development Perspectives, Vol 1, pp. 58-63.

Huot, S., McKay, J., Barbic, S., Wylie, A., Weis, D., Sherman, S.B. and Holsti, L. (2020). 'Tackling Complex Social Challenges within Neoliberal Constraints: The Context Shaping 'Intellectual Quality of Life' (IQoL) in a Canadian University'. Context. Societies, vol 10 no 26, pp. 1-13. DOI: 10.3390/soc10010026.

Kilpatrick, W. H. (1918/ 2006). O método do projecto [project method]. Pretexto editora e Edições Pedago, Lisboa

Klein, P. (2006). 'The challenges of scientific literacy: From the viewpoint of second-generation cognitive science'. International Journal of Science Education, vol 28 nº 2, pp.143-178.

Lozano, F.J. and Lozano, R. (2014). 'Developing the curriculum for a new Bachelor's degree in Engineering for Sustainable Development'. Journal of Cleaner Production, vol 64, pp. 136-146.

Max-Neef, M.A. (2005). 'Commentary: Foundations of Transdisciplinarity'. Ecological Economics, vol 53, pp. 5-16.

This is a post-peer-review, pre-copyedit version of an article published in International Journal of Sustainability in Higher Education. The final authenticated version is available online at:

https://www.emerald.com/insight/content/doi/10.1108/IJSHE-02-2020-0068/full/html?skipTracking=true. 
McGregor, S. L. T. (2014). 'TDMeme: A transdisciplinary meme'. Integral Leadership Review, vol 14 no 2, http://integralleadershipreview.com/11271-331-transdisciplinary-meme/

McGregor, S. L. T. (2015). 'Transdisciplinary knowledge creation', Gibbs P. T. (Ed.), Transdisciplinary professional learning and practice. New York, Springer, pp. 9-24.

Mitcham, C. and Frodeman, R. (2003). 'Extending science, technology, and society interdisciplinarity'. Science, Technology, \& Human Values, vol 28 nº 1, pp. 180-183.

Morin, E. (1991). Introdução ao pensamento complexo. Piaget, Lisboa.

Morin, E. (2002). 'Problemas de uma epistemologia complexa'. O Problema epistemológico da complexidade. Publicações Europa-América, Lisboa, pp. 13-40.

Nentwig, P. and Waddington, D. (Eds.) (2005). Making it relevant. Context based learning of science. Waxmann Publishing Co., New York.

Pellegrino, J. W. and Hilton, M. (Eds.) (2012). Education for life and work: Developing transferable knowledge and skills in the 21st Century. National Academic Press, Washington, DC.

Roberts, D.A. (2011). 'Competing visions of scientific literacy. The influence of a science curriculum policy image'. Linder, C.et al. (Eds.), Exploring the landscape of scientific literacy. Routledge, New York, pp. 11-27.

Segalas, J., Mulder, K.F. and Ferrer-Balas, D. (2012). "What do EESD "experts" think sustainability is? Which pedagogy is suitable to learn it?: Results from interviews and Cmaps analysis gathered at EESD 2008'. International Journal of Sustainability in Higher Education, Vol 13 no 3, pp. 293-304.

Sprain, L and Timpson, W.M. (2012). 'Pedagogy for Sustainability Science: Case-Based Approaches for Interdisciplinary Instruction'. Environmental Communication, Vol $6 \mathrm{n}^{\circ} 4$, pp. 532-550.

UNESCO (2015). Rethinking education. Towards a common global good? United Nations Educational, Scientific and Cultural Organization, Paris.

Wiek, A., Withycombe, L.and Redman, C.L. (2011). 'Key competencies in sustainability: A reference framework for academic program development'. Sustainability Science, Vol 6, pp. 203-218.

Wilson, S. and Zamberlan, L. (2012). 'Show me yours: Developind a faculty wide interdisciplinar initiative in built environment higher education'. Contemporary Issues In Education Research, vol. 5 n 4, pp. 331-342.

This is a post-peer-review, pre-copyedit version of an article published in International Journal of Sustainability in Higher Education. The final authenticated version is available online at: https://www.emerald.com/insight/content/doi/10.1108/IJSHE-02-2020-0068/full/html?skipTracking=true. 


\section{Bio-notes:}

\section{Cecília Galvão}

Full Professor at Institute of Education, University of Lisbon. She has a background in Biology and a $\mathrm{PhD}$ in Education. She coordinates the PhD Programme in Sustainability Science of the University of Lisbon, the PhD in Education and the Joint Master Degree in Scientific Culture and Outreach of Sciences. She also coordinates the Master program on Biology and Geology teaching. She coordinates the Science Education Research Group and develops research in science education and teachers' professional development. She was the Portuguese coordinator of EU FP6 PARSEL and FP7 SAILS projects. She is member of COST Action CA15212 Citizen Science (2016-2020).

\section{Cláudia Faria}

Principal Researcher and Invited Assistant Professor at the Institute of Education, University of Lisbon. She has a background in Biology and two $\mathrm{PhD}$, one $\mathrm{PhD}$ in Biology - Ecology and Biosystematics and one $\mathrm{PhD}$ in Science Education, both from the University of Lisbon. Her present research is related to the development of innovative science teaching and learning strategies in formal and non-formal contexts, such as museums, science centers, and research laboratories. Published more than 80 scientific papers, books and book chapters. She coordinated three national research projects, related with the promotion of scientific literacy, and participated in several national and international projects.

\section{Wanda Viegas}

$\mathrm{PhD}$ in Genetics from Wageningen University, The Netherlands. Jubilate Full Professor with a long teaching activity in the areas of Genetics and Cell Biology at the Instituto Superior de Agronomia, University of Lisbon and a research activity oriented to genomes dynamic behavior in terms of genetic and epigenetic changes mediated by genomes interactions and environmental factors, both in crops, model species and human cell lines. In this context, coordinated / participated in several research projects, and also oriented /co-oriented dozens of $\mathrm{PhD}$ and Masters students. Is the co-author of more than a hundred articles published in international journals.

This is a post-peer-review, pre-copyedit version of an article published in International Journal of Sustainability in Higher Education. The final authenticated version is available online at: https://www.emerald.com/insight/content/doi/10.1108/IJSHE-02-2020-0068/full/html?skipTracking=true. 


\section{Amélia Branco}

Assistant Professor at ISEG (ULisboa), in the Department of Social Sciences. She holds a PhD in Economic and Social History. Researcher at Economic and Social History Centre (GHES/CSG ISEG) that integrates the consortium Research in Social Sciences \& Management, where she makes part of the research group Sustainability and Policy. Her main research interests are forestry value chain along the $19^{\text {th }}$ and $20^{\text {th }}$ century, where she has several publications. Currently, she participates in two research projects: Capital Markets in Portugal $\left(19^{\text {th }}\right.$ century until WWI) and SustInAfrica - Sustainable intensification of food production through resilient farming systems in West \& North Africa.

\section{Luís F. Goulão}

$\mathrm{PhD}$ in Agronomic Engineering from the University of Lisbon. Assistant Professor at the School of Agriculture - University of Lisbon, focusing his research and teaching to link agriculture, food security and nutrition with Development outcomes. He is the coordinator of curricular units "Food Security and Food Policy", "Food Security and Global Dynamics" and "Tropical Farming and Agroforestry Systems" and member of the Scientific Committee of Doctoral Programmes "Development Studies" and "Sustainability Science". He is member of the Coordination Committee at the ISA's Research Centre "Linking Landscape, Environment, Agriculture and Food". Published more than 75 scientific and technical papers, book chapters, strategic briefs and more than 100 communications in congresses.

This is a post-peer-review, pre-copyedit version of an article published in International Journal of Sustainability in Higher Education. The final authenticated version is available online at: https://www.emerald.com/insight/content/doi/10.1108/IJSHE-02-2020-0068/full/html?skipTracking=true. 